\title{
Prospects for the Use of NF-кb Inhibitors to Stimulate the Functions of Regeneration-Competent Cells of Nerve Tissue and Neuroregeneration in Ethanol-Induced Neurodegeneration
}

\author{
Gleb Nikolaevich Zyuz'kov 1,* (D), Larisa Alexandrovna Stavrova ${ }^{1 \mathbb{D}}$, Larisa Arkad evna \\ Miroshnichenko $^{1}$ (D), Tatyana Yur`evna Polykova ${ }^{1}$ (D), Elena Vladislavovna Simanina ${ }^{1}$ (D) \\ 1 Goldberg Research Institute of Pharmacology and Regenerative Medicine, Tomsk National Research Medical Center, \\ Russian Academy of Sciences, Tomsk, Russia \\ * Correspondence: zgn@pharmso.ru;
}

Scopus Author ID 6508338421

Received: 30.06.2020; Revised: 14.07.2020; Accepted: 15.07.2020; Published: 18.07.2020

\begin{abstract}
The implementation of the concept of drug therapy of neurological disorders in chronic alcohol intoxication is, in some cases, unsuccessful. Promising is the search for new pharmacological targets among the intracellular signaling molecules of regenerating-competent cells. In the conditions of in vitro and in vivo modeling of ethanol-induced neurodegeneration, the role of NF-кB in the realization of the growth potential of neural progenitors and the secretion of neurotrophins by glial elements was studied. The absence of participation of NF-кB in the regulation of mitotic activity of neural SC (NSC) and of neuronal-committed progenitors (NCP) in their optimal living conditions and in the influence of ethanol in vitro is shown. At the same time, NF-кB hinders the implementation of the NSC specialization process. The prolonged introduction of ethanol per os mice was accompanied by the appearance of an inhibitory value in NF-кB in relation to the intensity of progenitors proliferation. The blockade of NF-KB of NSC and NCP animals with neurodegeneration caused the progression of their cell cycle. The participation of NF-кB in the secretory function of astrocytes and oligodendrogliocytes has been established. The inactivation of the nuclear transcription factor led to a decrease in their production of neurotrophins, including in the case of ethanol. At the same time, there were no changes from the microglia functioning.
\end{abstract}

Keywords: neural stem cells; signal transduction; NF-кB; neuroglia; targeted therapy; regenerative medicine; ethanol-induced neurodegeneration.

(C) 2020 by the authors. This article is an open-access article distributed under the terms and conditions of the Creative Commons Attribution (CC BY) license (https://creativecommons.org/licenses/by/4.0/).

\section{Introduction}

The decompensation of adaptation mechanisms in chronic alcohol intoxication leads not only to impaired cognitive functions and neurological disorders but also to the development of visceral dysregulation diseases [1-3]. The implementation of the concept of drug therapy of these conditions, which is currently used in practical healthcare, based on the effect on mature cellular elements of the nervous tissue preserved in the conditions of the pathology, is, in some cases, unsuccessful [4-7]. Available drugs are often not able to not only restore the lost functions of the central nervous system but also prevent the progression of the pathology even after alcohol deprivation. In this regard, it seems relevant to a search for fundamentally new approaches to the treatment of encephalopathy caused by chronic use of ethanol. 
The previously obtained information about the peculiarities of intracellular signaling in histogenetically and functionally heterogeneous progenitor cells $[9,10]$ served as the basis for creating a new direction of targeted therapy in regenerative medicine - "Strategies for the pharmacological regulation of intracellular signal transduction in regenerative competent cells" [11]. That, this approach involves the use as targets of individual links of intracellular signal transduction not only in various progenitor elements but also in cells of the microenvironment of tissues. Moreover, an additional circumstance that testifies to the possible selective stimulation of the regeneration of various organs is the tissue specificity of certain types and isoforms of a number of signaling proteins (including products of alternative splicing) [11].

The identification of the role of individual signaling molecules (potential pharmacological targets) in the regulation of the cell cycle of the parent element is a key stage in the development of this direction. It is known that NF-кB plays an important role in determining the proliferative and differentiating status of parent cells $[9,12]$, as well as in the production of cytokines by neuroglia [13]. However, there is no detailed understanding of the significance of the nuclear transcription factor in the functioning of progenitor and glial elements of nervous tissue under conditions of ethanol intoxication.

The aim of the work was to study the participation of NF-кB in the realization of the growth potential of neural tissue precursor cells (NSCs, CPN) and the production of neurotrophic growth factors by different fractions of glia cells during ethanol-induced neurodegeneration.

\section{Materials and Methods}

\subsection{Chemicals and drugs.}

MACS Neuro Medium; anti-PSA-NCAM MicroBeads; anti-ACSA-2 MicroBead Kit; Anti-O4 MicroBeads; Anti-CD11b (Microglia) MicroBeads (all manufactured by Miltenyi Biotec, Germany); NF-кB inhibitor «aurothiomalate» (Calbiochem, USA); hydroxyurea (Calbiochem, USA); plastic plates for cultural studies («Costar», USA).

\subsection{Animals and experimental design.}

All animal experiments were carried out in accordance with the U.K. Animals (Scientific Procedures) Act, 1986 and associated guidelines, EU Directive 2010/63/EU for animal experiments. The study was approved by the Institute's local Ethics Committee. Experiments were carried out on C57B1/6 mice $(n=84)$ at the age of 2-2.5 months, weighing 20-22 g. Animals of the 1 st category (conventional outbred rats and linear mice) were obtained from Experimental Biological Models Department of Goldberg Research Institute of Pharmacology and Regenerative Medicine (Tomsk, Russia) (certificate available). Before the beginning of experiments (during 10 days) and over the study period, animals were contained in the vivarium (air temperature $20-22^{\circ} \mathrm{C}$, humidity 50-60\%) in plastic cages (10-15 mice) on a normal diet (solid diet pellets (Limited Liability Company «Assortiment Firm», Sergiev Posad city, Russia), water ad libitum. In order to exclude seasonal fluctuations of studied parameters, all the experiments were performed in the autumn-winter period. The animals were removed from the experiment (sacrificed) using $\mathrm{CO}_{2}$ cameras, except for the groups of rats used for histological examination (these animals were killed by decapitation).

Using the cultural methods, we studied the direct effect of the NF-KB inhibitor aurothiomalate (Calbiochem, USA) (at a concentration of $50 \mu \mathrm{M}$ ) on the realization of the 
growth potential of neural tissue precursor cells (NSC, CPN) and the secretion of neurotrophins by glial cells (astrocytes, oligodendrogliocytes, microglia) in the conditions of modeling ethanol-induced neurodegeneration in vitro and in vivo.

In vitro ethanol-induced neurodegeneration was obtained by adding ethanol to the culture medium at a concentration $(65 \mathrm{mM})$. In vivo modeling of the pathological state was carried out by oral administration of a $30 \%$ solution of $\mathrm{C}_{2} \mathrm{H}_{5} \mathrm{OH}$ (through a probe daily at a dose of $3 \mathrm{~g} / \mathrm{kg} / \mathrm{day}$ for 8 weeks) [14]. In this case, instead of drinking water of free access, a $5 \%$ solution of ethyl alcohol was used. Cellular material for the study was taken 10 days after the end of the introduction of ethanol in vivo. The control group in the same model was injected with distilled water in an equivalent volume (mice had free access to drinking water).

\subsection{Determination of the progenitors' content.}

NSCs were studied during the cultivation of unfractionated cells of the subventricular zone of the cerebral hemispheres. To study committed neuronal precursors (CPN) from cells of the subventricular zone of the brain using an immunomagnetic separator "MIniMACS Cell Separator" (Miltenyi Biotec, Germany), PSA-NCAM (CD56 +) cells were obtained by positive selection [15] (using appropriate antibody kits according to the methodological manufacturer's instructions). The obtained unfractionated and PSA-NCAM + cells at a concentration of $10^{5} /$ $\mathrm{ml}$ were incubated in MACS Neuro Medium (Miltenyi Biotec, Germany) for 5 days in a CO2 incubator at $37^{\circ} \mathrm{C}, 5 \% \mathrm{CO} 2$ and $100 \%$ air humidity. After incubation in both cases (during the cultivation of unfractionated cells and PSA-NCAM + cells), the content of clonogenic cells, their mitotic activity, and intensity of specialization were calculated. The number of NSC and $\mathrm{CPN}$ was determined by the yield in the respective cultures of colony-forming units (CFU, colonies containing more than 100 cells). The proliferative activity of the progenitor cells was assessed by the method of cell suicide using hydroxyurea $(1 \mu \mathrm{M})$ [9]. The pool of CFU in the S-phase of the cell cycle was determined according to the formula: $\mathrm{N}=[(\mathrm{a}-\mathrm{b}) / \mathrm{a}] \times 100 \%$, where $\mathrm{a}$ is the average for the group the number of CFU from cells not treated with hydroxyurea; $b$ the average for the group the number of CFU from cells treated with hydroxyurea. The intensity of the processes of specialization (differentiation/maturation) of progenitor elements was determined by calculating the ratio of the corresponding cluster-forming ( $\mathrm{ClFU}$, neurospheres of 30 - 100 cells) to CFU (differentiation index) [2, 14].

\subsection{Study of neurotrophins secretion by cells of nerve tissue in vitro.}

Individual fractions of glial elements (astrocytes - ACSA-2 + cells [16]; oligodendrogliocytes - O4 + cells [17]; microglia - CD11b + cells [18, 19]) were also obtained from the subventricular zone of the cerebral hemispheres using immunomagnetic positive selection (using appropriate antibody kits according to the guidelines of Miltenyi Biotec, Germany) The isolated cells at a concentration of $2 \times 10^{6} / \mathrm{ml}$ were incubated in MACS Neuro Medium (Miltenyi Biotec, Germany) for 2 days in a $\mathrm{CO} 2$ incubator at $37^{\circ} \mathrm{C}, 5 \% \mathrm{CO} 2$ and $100 \%$ air humidity to obtain supernatants. To determine their secretory activity (production of neurotrophins, a combination of growth factors active against CFU), the effect of conditioned media on the level of neurosphere formation in the test system was studied [9]. 


\subsection{Statistical Analysis.}

The results were analyzed with one-way ANOVA followed by Dunnett's test, Wilcoxon's test for dependent samples, and Mann-Whitney test for independent samples. The data are expressed as arithmetic means and standard errors. The significance level was $\mathrm{p}=0.05$ [20].

\section{Results and Discussion}

\subsection{The effect of ethanol on the functioning of various types of regeneration-competent cells of nervous tissue.}

The introduction of a neurotoxic dose of ethanol into the culture medium [21] was not accompanied by a change in the output of CFU and CIFU from both unfractionated cells of the subventricular zone of the brain (Fig. 1, A, B) and the population of PSA-NCAM + cells (Fig. $2, \mathrm{~A}, \mathrm{~B})$.
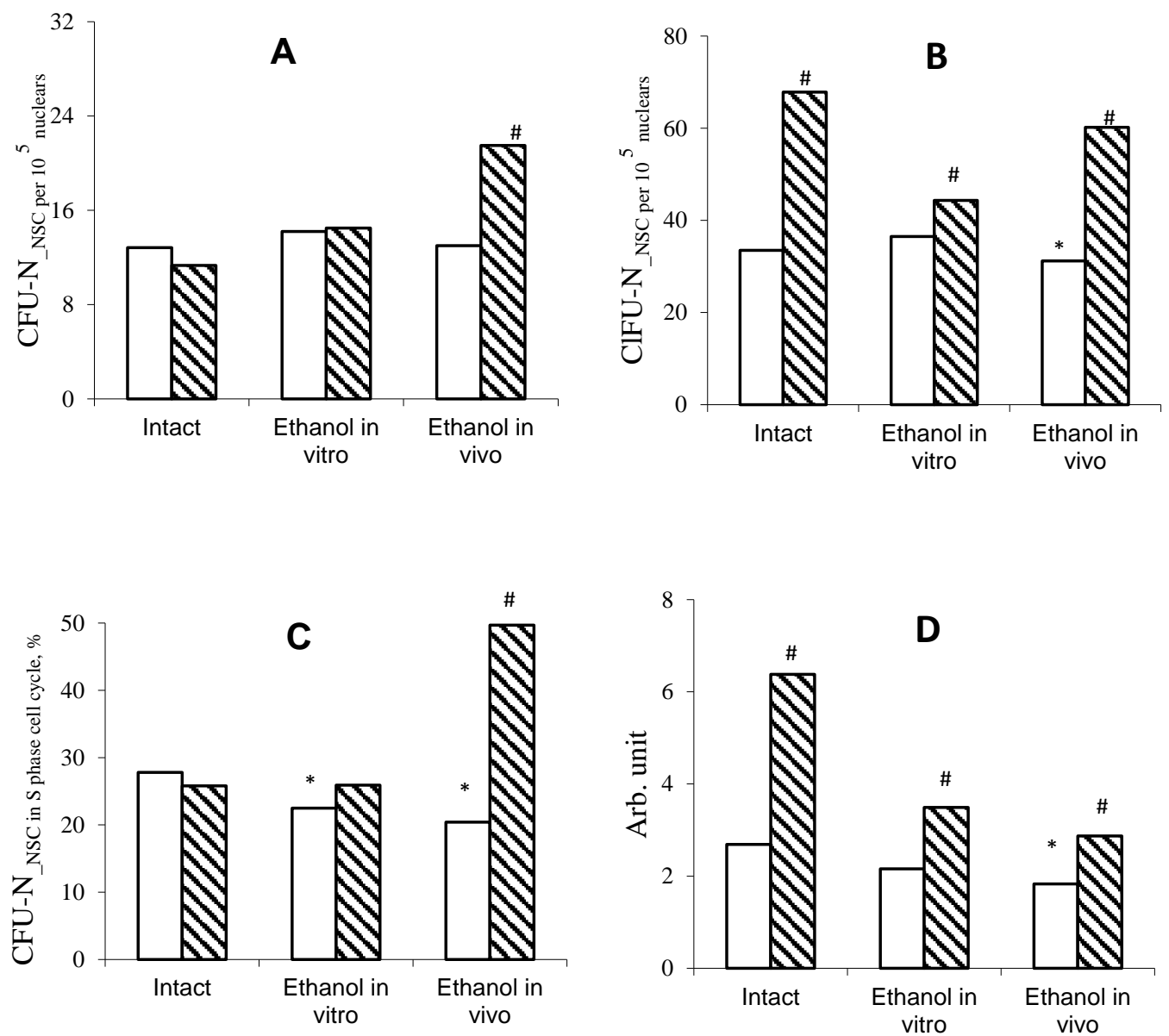

Figure 1. Number of multipotent neural stem cells: colony- (CFU-N_NSC) (A), cluster-forming (CIFU-N_NSC) units (B); proliferative activity (CFU-N_NSC in the S phase of the cell cycle) (B) and index of differentiation (CIFU-N_NSC / CFU-N_NSC) (D) in the cell culture of the SVZ: intact C57B1/6 mice without alcohol (intact), with alcohol (ethanol in vitro); and mice after prolonged administration of ethanol per os (ethanol in vivo). White bars - without NF-кB inhibitor; shaded columns - when an NF-кB inhibitor is added to the medium; * the significance of differences in indicators with intact was noted at $\mathrm{p}<0.05$; \# - the significance of differences with the group without inhibitor was noted at $\mathrm{p}<0.05$.

At the same time, a significant decrease in the mitotic activity of multipotent (CFUH_NSC) and committed predecessors (CFU-H_PSA-NCAM +) was noted (to $77.3 \%$ and $80.8 \%$ of the 
background values, respectively). However, these changes were most pronounced in animals after prolonged administration of ethanol per os. The violation of the proliferative potential of progenitor cells, in this case, was accompanied by a decrease in the output of CFU-H_PSA-NCAM + (Fig. 2, A) and the intensity of NSC specialization (Fig. 1, D). In addition, ethanol caused similar shifts in the secretory function of all types of glial elements. A decrease in the level of colony formation in test systems containing conditioned media of astrocytes, oligodendrogliocytes, and microglia were noted (Fig. 3).

Moreover, with respect to $\mathrm{CD} 11 \mathrm{~b}+$ cells, this phenomenology took place when modeling in vitro and in vivo neurodegeneration, and in the case of studying ACSA-2 + and $\mathrm{O} 4+$ cells, only in chronic alcoholization of the body. Thus, astrocytes and oligodendrocytes, which play the most significant role in providing neurotrophic function with glia [6,9], turned out to be less (compared to microglia) with a negative effect of ethanol on the studied parameter. At the same time, it is obvious that the dynamics of changes detected during testing of the activity of supernatants, in many respects, depend not only on the production of neurotrophins by cells. The methodology used reflects a parameter of the resulting nature, which is also dependent on the production of colony formation inhibitors, including proinflammatory cytokines [22, 23].

In general, the revealed phenomena largely corresponded to the data we obtained earlier [21] on decompensation of the CNS cellular renewal systems, which is especially pronounced during prolonged systemic exposure to alcohol on the body. At the same time, based on the results obtained, it follows that both the progenitor and glial elements of the nervous tissue, including astrocytes, are equally sensitive to the toxic effect of $\mathrm{C}_{2} \mathrm{H}_{5} \mathrm{OH}$ (despite the most pronounced adaptive reserves [24]).

3.2. The role of $N F-\kappa B$ in implementation functions various types of progenitor cells of nervous tissue in ethanol-induced neurodegeneration.

A study of the role of NF-кB in the realization of the growth potential of intact progenitor cells did not reveal the involvement of the nuclear transcription factor in the regulation of the mitotic activity of NSCs and committed neuron precursors under conditions of their optimal vital activity and when exposed to ethanol in vitro (Fig. 1, 2). In both cases, aurothiomalate did not affect the total content of CFU-H_NSC and CFU-H_PSA-NCAM +, as well as the number of their forms in the $\mathrm{S}$ phase of the cell cycle. At the same time, impaired signal transmission through NF-кB led to a significant acceleration of differentiation/maturation of intact NSCs (Fig. 1, D).

Other results were obtained in the study of progenitor cells of animals subjected to prolonged administration of alcohol. The formation of ethanol-induced pathogenic biochemical "continuum" in vivo $[2,24]$ was accompanied by the appearance of a negative effect of NF-кB on the fission rate of the progenitors. Blockade of NF-кB in NSC and CPN of animals with neurodegeneration caused a significant increase in the output of CFU-H_NSC and CFU-H_PSANCAM + against the background of stimulation of the progression of their cell cycle (Fig. 1, B; 2, B). At the same time, the inhibitory role of NF-кB with respect to the implementation of the process of specialization of the parent cells was preserved (Fig. 1, D). 

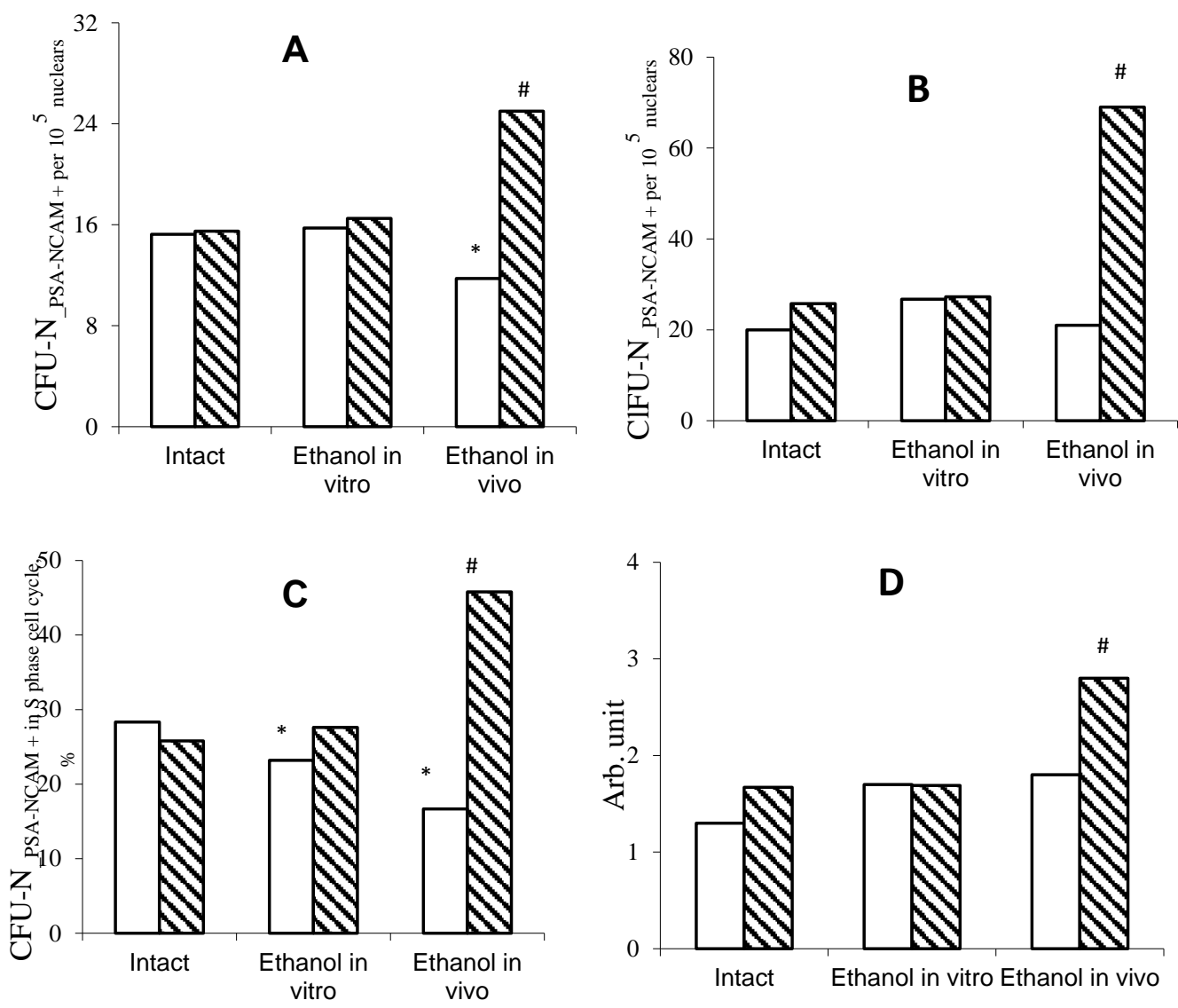

Figure 2. Number of multipotent neural stem cells: colony- (CFU-N_PSA-NCAM+) (A), cluster-forming (ClFU-


and index of differentiation (ClFU-N_PSA-NCAM+ / CFU-N_PSA-NCAM+) (D) in the cell culture of the SVZ: intact C57B1/6 mice without alcohol (intact), with alcohol (ethanol in vitro); and mice after prolonged administration of ethanol per os (ethanol in vivo). White bars - without NF-кB inhibitor; shaded columns - when an NF-кB inhibitor is added to the medium; * - the significance of differences in indicators with intact was noted at $\mathrm{p}<0.05$; \# - the significance of differences with the group without inhibitor was noted at $\mathrm{p}<0.05$.

3.2. The role of $N F-\kappa B$ in neurotrophins secretion by cells of nerve tissue in ethanol-induced neurodegeneration.

Changes in the functioning of various types of neuroglia cells, depending on their living conditions during a blockade of the nuclear transcription factor, were even more ambiguous. Thus, inactivation of NF-KB signaling in all cases (intact cells without alcohol; cells exposed to $\mathrm{C} 2 \mathrm{H} 5 \mathrm{OH}$ in vitro; animal cells after ethanol intake in vivo) was accompanied by a significant decrease in the production of neurotrophins by astrocytes (Fig. 3, A). The ability of microglia to influence the realization of the growth potential of progenitor cells (due to the production of humoral factors) under the influence of aurothiomalate was manifested only in a medium that did not contain $\mathrm{C} 2 \mathrm{H} 5 \mathrm{OH}$ (Fig. 2, B). At the same time, the NF-кB inhibitor: suppressed the production of growth factors by intact oligodendrogliocytes under the conditions of their cultivation in a medium without alcohol; stimulated such when introducing ethanol in vitro; and did not affect the functioning of $\mathrm{O} 4+$ cells of mice with alcohol encephalopathy (Fig. 3, В). The revealed loss of NF-кB involvement in the secretory function of oligodendrogliocytes under conditions of chronic ethanol intoxication indicates a higher vulnerability of the indicated mechanism than astrocytes, obviously determined by a fundamentally different 
(unrelated to the regulation of the state of the NSC pool) the primary purpose of this type of neuroglia $[17,25]$.
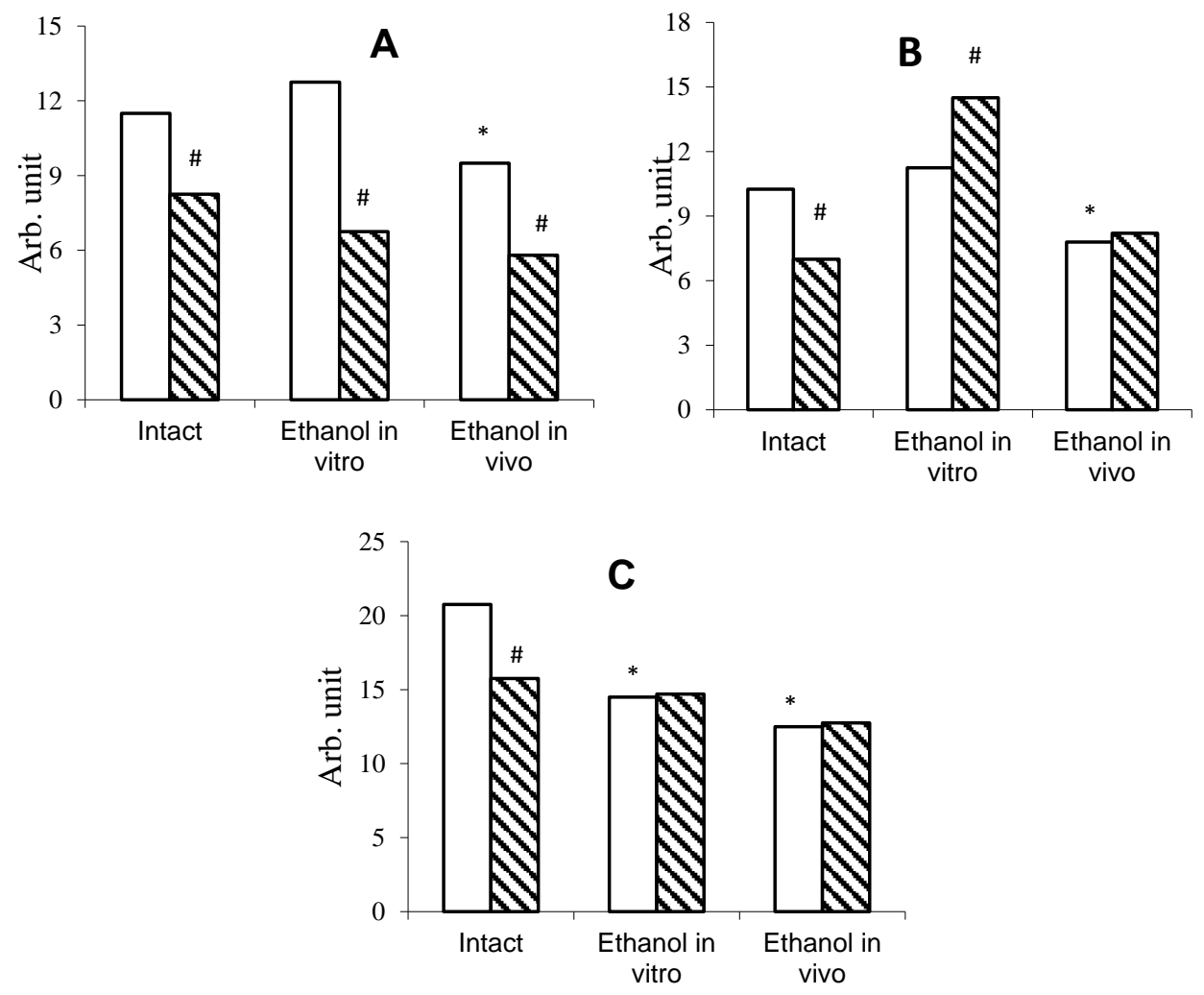

Figure 3. The effect of conditioned media of astrocytes (A), oligodendrogliocytes (B), and microglia (C) on the level of neurosphere formation in the test system. Conditioned media were obtained after culturing intact cells from the subventricular zone of the brain of intact C57B1/6 mice in a medium without alcohol (intact) and with alcohol (ethanol in vitro), and from mouse cells after prolonged administration of ethanol per os (ethanol in vivo). White bars - without NF-KB inhibitor; shaded columns - when an NF-KB inhibitor is added to the medium; * - the significance of differences in indicators with intact was noted at $\mathrm{p}<0.05$; \# - the significance of differences with the group without signaling molecule inhibitor was noted at $\mathrm{p}<0.05$

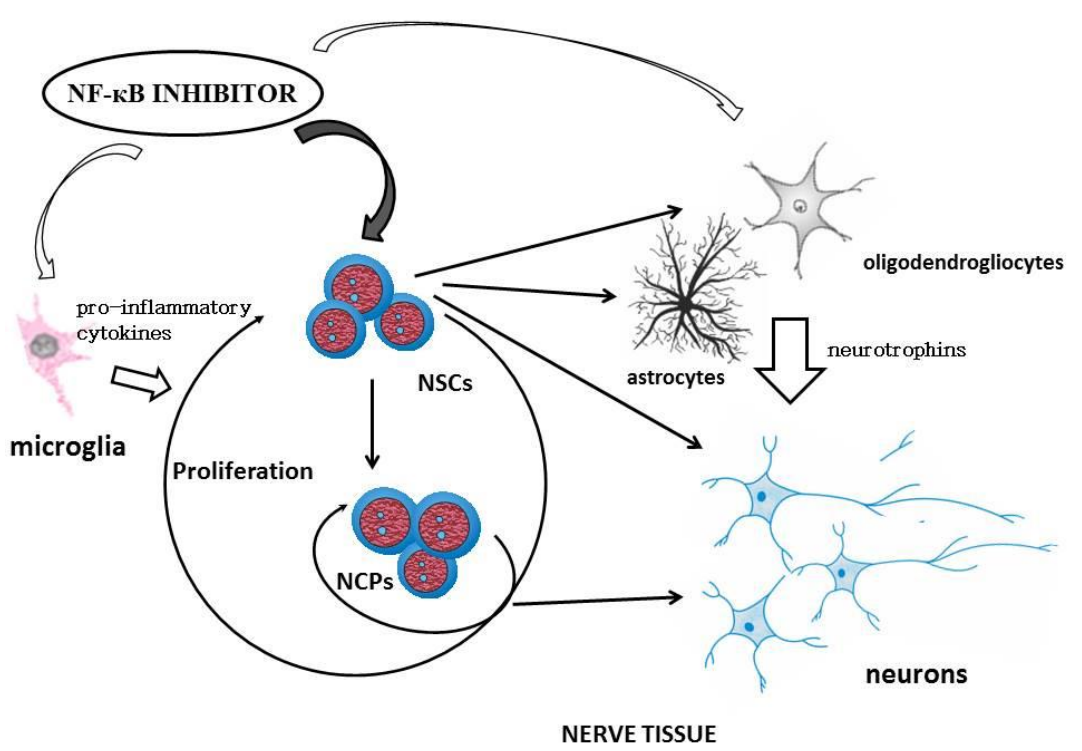

Figure 4. The effect of the NF-kB inhibitor on the regeneration-competent cells of the nerve tissue. NSCs neural stem cells, NCPs - neuronal-committed progenitor cells. Black arrows are a stimulating influence; white arrows are an inhibitory effect. 


\section{Conclusions}

In general, the obtained results confirm the literature on the involvement of NF-кBmediated pathways in determining the state of pools of various types of regeneration-competent cells of the nervous tissue $[9,26,27]$. It was found that one of the key roles of NF-кB in the conditions of optimal NSC life is the preservation of their multipotency due to the inhibition of the specialization process (differentiation), and thereby preventing the depletion of the "deep reserve" of CNS regeneration [28]. At the same time, pronounced participation of the nuclear transcription factor in the manifestations of decompensation of the functions of NSC and CPN in severe ethanol-induced neurodegeneration was revealed. Under conditions of prolonged toxic effects, NF-кB phosphorylation leads to a cell cycle arrest. These circumstances support the promise of using inhibitors of NF- $\mathrm{KB}$ activity/expression as agents with regenerative activity for the treatment of diseases of the nervous system of alcoholic genesis (Fig. 4). Moreover, it is important that such a medical intervention will not interfere with the functioning of intact NSCs and CPN, since it is assumed that during the course of therapy there will be a regular "normalization" (sanogenetic transformation) of the intracellular signaling pattern in competent regenerative cells formed by de novo $[2,24]$. In addition, the blockade of NF-кB in the central nervous system can reduce the intensity of the neuroinflammatory (associated with the production of pro-inflammatory cytokines by glial cells), which has a significant pathogenic value in brain damage during chronic ethanol intoxication [29-33]. At the same time, during the further development of the proposed therapy approach (due to the blockade of NF-кB) of alcohol-associated pathology, the revealed stimulating role of NF-кB in the production of neurotrophins by astroglia should be taken into account. These elements of the microenvironment can fundamentally affect not only the intensity and outcome of reparative processes in the nervous tissue but also the functioning of mature neurons [24, 25, 30]. The findings suggest the need for research on the possibility of using NF- $\mathrm{\kappa B}$ inhibitors for the therapy of alcoholic encephalopathy.

\section{Funding}

This research was funded by the Russian Foundation for Basic Research (RFBR), grant number 18-015-00013.

\section{Acknowledgments}

This research has no acknowledgment.

\section{Conflicts of Interest}

The authors declare no conflict of interest.

\section{References}

1. Koeppen A.H. The neuropathology of the adult cerebellum. Handb Clin Neurol. 2018, 154, 129-149, https://doi.org/10.1016/B978-0-444-63956-1.00008-4.

2. Zyuz'kov, G.N.; Miroshnichenko, L.A.; Polyakova, T.Y.; Stavrova, L.A.; Simanina, E.V.; Zhdanov, V.V. Specific Roles of JAKs and STAT3 in Functions of Neural Stem Cells and Committed Neuronal Progenitors during Ethanol-Induced Neurodegeneration. Bulletin of Experimental Biology and Medicine 2020, 168, 356360, https://doi.org/10.1007/s10517-020-04708-w. 
3. Zhang, K.; Wang, H.; Xu, M.; Frank, J.A.; Luo, J. Role of MCP-1 and CCR2 in ethanol-induced neuroinflammation and neurodegeneration in the developing brain. Journal of Neuroinflammation 2018, 15, https://doi.org/10.1186/s12974-018-1241-2.

4. Tateno, M.; Saito, T. Biological Studies on Alcohol-Induced Neuronal Damage. Psychiatry Investig. 2008, 5, 21-27, https://doi.org/10.4306/pi.2008.5.1.21.

5. Brust, J.C. Acute withdrawal: diagnosis and treatment. Handb Clin Neurol. 2014, 125, 123-31, https://doi.org/10.1016/B978-0-444-62619-6.00008-2.

6. Coleman Jr, L.G.; He, J.; Lee, J.; Styner, M.; Crews, F.T. Adolescent Binge Drinking Alters Adult Brain Neurotransmitter Gene Expression, Behavior, Brain Regional Volumes, and Neurochemistry in Mice. Alcoholism: Clinical and Experimental Research 2011, 35, 671-688, https://doi.org/10.1111/j.15300277.2010.01385.x.

7. Jordaan, G.P.; Emsley, R. Alcohol-induced psychotic disorder: a review. Metabolic Brain Disease 2014, 29 , 231-243, https://doi.org/10.1007/s11011-013-9457-4.

8. Nixon, K. Alcohol and adult neurogenesis: Roles in neurodegeneration and recovery in chronic alcoholism. Hippocampus 2006, 16, 287-295, https://doi.org/10.1002/hipo.20162.

9. Zyuz'kov, G.N.; Zhdanov, V.V.; Udut, E.V.; Miroshnichenko, L.A.; Polyakova, T.Y.; Stavrova, L.A.; Chaikovskii, A.V.; Simanina, E.V.; Minakova, M.Y.; Udut, V.V. Peculiarities of Intracellular Signal Transduction in the Regulation of Functions of Mesenchymal, Neural, and Hematopoietic Progenitor Cells. Bulletin of Experimental Biology and Medicine 2019, 167, 201-206, https://doi.org/10.1007/s10517-01904491-3.

10. Zyuz'kov, G.N.; Zhdanov, V.V.; Udut, E.V.; Miroshnichenko, L.A.; Simanina, E.V.; Polyakova, T.Y.; Stavrova, L.A.; Udut, V.V.; Minakova, M.Y.; Dygai, A.M. Involvement of JAK1, JAK2, and JAK3 in Stimulation of Functional Activity of Mesenchymal Progenitor Cells by Fibroblast Growth Factor. Bulletin of Experimental Biology and Medicine 2016, 162, 240-243, https://doi.org/10.1007/s10517-016-3585-X.

11. Zyuz'kov, G.N.; Zhdanov, V.V.; Udut, E.V.; Miroshnichenko, L.A.; Polyakova, T.Y.; Stavrova, L.A.; Udut, V.V. Strategy of Pharmacological Regulation of Intracellular Signal Transduction in RegenerationCompetent Cells. Bulletin of Experimental Biology and Medicine 2019, 166, 448-455, https://doi.org/10.1007/s10517-019-04370-X.

12. Zhou, K.; Guo, S.; Tong, S.; Sun, Q.; Li, F.; Zhang, X.; Qiao, Y.; Liang, G. Immunosuppression of Human Adipose-Derived Stem Cells on T Cell Subsets via the Reduction of NF-kappaB Activation Mediated by PD-L1/PD-1 and Gal-9/TIM-3 Pathways. Stem Cells and Development 2018, 27, 1191-1202, https://doi.org/10.1089/scd.2018.0033.

13. Li, Y.X.; Sibon, O.C.M.; Dijkers, P.F. Inhibition of NF- $\kappa$ B in astrocytes is sufficient to delay neurodegeneration induced by proteotoxicity in neurons. Journal of Neuroinflammation 2018, 15, 261, https://doi.org/10.1186/s12974-018-1278-2.

14. Zyuz'kov, G.N.; Miroshnichenko, L.A.; Polyakova, T.Y.; Stavrova, L.A.; Simanina, E.V.; Agafonov, V.I.; Udut, E.V.; Zhdanov, V.V. Role of MAPK ERK1/2 and p38 in the Realization of Growth Potential of Various Types of Regeneration-Competent Cells in Mouse Neural Tissue during Ethanol-Induced Neurodegeneration In Vitro. Bulletin of Experimental Biology and Medicine 2019, 167, 229-232, https://doi.org/10.1007/s10517-019-04497-x.

15. Seki, T. Expression patterns of immature neuronal markers PSA-NCAM, CRMP-4 and NeuroD in the hippocampus of young adult and aged rodents. Journal of Neuroscience Research 2002, 70, 327-334, https://doi.org/10.1002/jnr.10387.

16. Kantzer, C.G.; Boutin, C.; Herzig, I.D.; Wittwer, C.; Reiß, S.; Tiveron, M.C.; Drewes, J.; Rockel, T.D.; Ohlig, S.; Ninkovic, J.; Cremer, H.; Pennartz, S.; Jungblut, M.; Bosio, A. Anti-ACSA-2 defines a novel monoclonal antibody for prospective isolation of living neonatal and adult astrocytes. Glia 2017, 65, 9901004, https://doi.org/10.1002/glia.23140.

17. Werneburg, S.; Fuchs, H.L.S.; Albers, I.; Burkhardt, H.; Gudi, V.; Skripuletz, T.; Stangel, M.; GerardySchahn, R.; Hildebrandt, H. Polysialylation at Early Stages of Oligodendrocyte Differentiation Promotes Myelin Repair. The Journal of Neuroscience 2017, 37, 8131-8141, https://doi.org/10.1523/JNEUROSCI.1147-17.2017.

18. Sousa, C.; Golebiewska, A.; Poovathingal, S.K.; Kaoma, T.; Pires-Afonso, Y.; Martina, S.; Coowar, D.; Azuaje, F.; Skupin, A.; Balling, R.; Biber, K.; Niclou, S.P.; Michelucci, A. Single-cell transcriptomics reveals distinct inflammation-induced microglia signatures. EMBO reports 2018, 19, https://doi.org/10.15252/embr.201846171.

19. Martin, E.; El-Behi, M.; Fontaine, B.; Delarasse, C. Analysis of Microglia and Monocyte-derived Macrophages from the Central Nervous System by Flow Cytometry. J Vis Exp. 2017, 22, 55781, https://doi.org/10.3791/55781.

20. Curtis, M.J.; Bond, R.A.; Spina, D.; Ahluwalia, A.; Alexander, S.P.A.; Giembycz, M.A.; Gilchrist, A.; Hoyer, D.; Insel, P.A.; Izzo, A.A.; Lawrence, A.J.; MacEwan, D.J.; Moon, L.D.F.; Wonnacott, S.; Weston, A.H.; McGrath, J.C. Experimental design and analysis and their reporting: new guidance for publication in BJP. British Journal of Pharmacology 2015, 172, 3461-3471, https://doi.org/10.1111/bph.12856. 
21. Zyuz’kov, G.N.; Miroshnichenko, L.A.; Udut, E.V.; Chaikovskii, A.V.; Polyakova, T.Y.; Simanina, E.V.; Stavrova, L.A.; Agafonov, V.I.; Zhdanov, V.V. Functional State of Various Types of RegenerationCompetent Cells in the Nervous Tissue in Ethanol-Induced Neurodegeneration. Bulletin of Experimental Biology and Medicine 2019, 166, 317-320, https://doi.org/10.1007/s10517-019-04341-2.

22. Amin, F.U.; Shah, S.A.; Kim, M.O. Glycine inhibits ethanol-induced oxidative stress, neuroinflammation and apoptotic neurodegeneration in postnatal rat brain. Neurochemistry International 2016, 96, 1-12, https://doi.org/10.1016/j.neuint.2016.04.001.

23. Zhou, K.; Guo, S.; Tong, S.; Sun, Q.; Li, F.; Zhang, X.; Qiao, Y.; Liang, G. Immunosuppression of Human Adipose-Derived Stem Cells on T Cell Subsets via the Reduction of NF-kappaB Activation Mediated by PD-L1/PD-1 and Gal-9/TIM-3 Pathways. Stem Cells and Development 2018, 27, 1191-1202, https://doi.org/10.1089/scd.2018.0033.

24. Takeuchi, N.; Izumi, S. Maladaptive plasticity for motor recovery after stroke: mechanisms and approaches. Neural Plast. 2012, 2012.

25. Lattke, M.; Reichel, S.N.; Baumann, B. NF-кB-mediated astrocyte dysfunction initiates neurodegeneration. Oncotarget 2017, 8, 50329-50330, https://doi.org/10.18632/oncotarget.18320.

26. Rolando, C.; Erni, A.; Grison, A.; Beattie, R.; Engler, A.; Gokhale, Paul J.; Milo, M.; Wegleiter, T.; Jessberger, S.; Taylor, V. Multipotency of Adult Hippocampal NSCs In\&\#xa0;Vivo Is Restricted by Drosha/NFIB. Cell Stem Cell 2016, 19, 653-662, https://doi.org/10.1016/j.stem.2016.07.003.

27. Kounatidis, I.; Chtarbanova, S.; Cao, Y.; Hayne, M.; Jayanth, D.; Ganetzky, B.; Ligoxygakis, P. NF$\& \# x 3 b a ; B$ Immunity in the Brain Determines Fly Lifespan in Healthy Aging and Age-Related Neurodegeneration. Cell Reports 2017, 19, 836-848, https://doi.org/10.1016/j.celrep.2017.04.007.

28. Zyuz'kov, G.N.; Losev, E.A.; Chaikovskii, A.V.; Suslov, N.I.; Zhdanov, V.V.; Udut, E.V.; Miroshnichenko, L.A.; Simanina, E.V.; Polyakova, T.Y.; Povet'eva, T.N.; Nesterova, Y.V.; Stavrova, L.A.; Udut, V.V.; Minakova, M.Y.; Dygai, A.M. Psychopharmacological Effects of Alkaloid Z77 under Conditions of Posthypoxic Encephalopathy and Mechanisms of Their Development. Bulletin of Experimental Biology and Medicine 2016, 161, 45-49, https://doi.org/10.1007/s10517-016-3341-2.

29. Faden, A.I.; Wu, J.; Stoica, B.A.; Loane, D.J. Progressive inflammation-mediated neurodegeneration after traumatic brain or spinal cord injury. British Journal of Pharmacology 2016, 173, 681-691, https://doi.org/10.1111/bph.13179.

30. Saito, M.; Chakraborty, G.; Hui, M.; Masiello, K.; Saito, M. Ethanol-Induced Neurodegeneration and Glial Activation in the Developing Brain. Brain Sciences 2016, 6, 31, https://doi.org/10.3390/brainsci6030031.

31. Tajuddin, N.; Kim, H.-Y.; Collins, M.A. PARP Inhibition Prevents Ethanol-Induced Neuroinflammatory Signaling and Neurodegeneration in Rat Adult-Age Brain Slice Cultures. Journal of Pharmacology and Experimental Therapeutics 2018, 365, 117-126, https://doi.org/10.1124/jpet.117.245290.

32. Martorana F.; Foti M.; Virtuoso A.; Gaglio D.; Aprea F.; Latronico T.; Rossano R.; Riccio P.; Papa M.; Alberghina L.; Colangelo A.M. Differential Modulation of NF- $\kappa$ B in Neurons and Astrocytes Underlies Neuroprotection and Antigliosis Activity of Natural Antioxidant Molecules. Oxidative Medicine and Cellular Longevity. 2019; 2019: 8056904, https://doi: 10.1155/2019/8056904

33. Da Pozzo E.; Tremolanti C.; Costa B.; Giacomelli C.; Milenkovic V.M.; Bader S.; Wetzel C.H.; Rupprecht R.; Taliani S.; Da Settimo F.; Martini C. Microglial Pro-Inflammatory and Anti-Inflammatory Phenotypes Are Modulated by Translocator Protein Activation. International journal of molecular sciences. 2019, 20, 4467. https://doi.org/10.3390/ijms20184467 